\title{
An Optimality-Theoretic Analysis of the Acquisition of English Sentence Stress Based on Acoustic Data
}

\author{
Wen $\mathrm{Ji}^{1}$ and Yun Liu ${ }^{2}{ }^{2}$ \\ ${ }^{1}$ Hefei Technology College, Hefei, Anhui 238000, China \\ ${ }^{2}$ School of Information Engineering, Chaohu University, Chaohu, China \\ Correspondence should be addressed to Yun Liu; 054053@chu.edu.cn
}

Received 11 January 2021; Revised 14 February 2021; Accepted 3 March 2021; Published 25 March 2021

Academic Editor: M. Irfan Uddin

Copyright $(92021$ Wen Ji and Yun Liu. This is an open access article distributed under the Creative Commons Attribution License, which permits unrestricted use, distribution, and reproduction in any medium, provided the original work is properly cited.

The present study adopts both empirical and theoretical methods for the analysis of the acquisition of English sentence stress based on Optimality Theory, aiming to overcome mispronunciation of English sentence stress. Optimality Theory has a dramatic impact on most areas in linguistics besides phonology. The acoustic software Praat is chosen to collect and label data as the basis of the empirical method. Then, through analyzing the four major principles of distribution of sentence stress (content words stressed principle, rightmost words stressed principle, leftmost words stressed principle, and new information priority principle) and based on the analysis of Optimality Theory, the software Praat, and SPSS, the researcher can present the following findings: firstly, the constraint hierarchical ranking of nonnative speakers is DEP-IO $>>$ NEW-IP $>>$ ALIGN-IP-LEFT $>>$ ALIGN-IP-RIGHT. Secondly, the native speakers also undergo the demotion of constraint hierarchical ranking: NEW-IP $>>$ DEP-IO $>>$ ALIGN-IPRIGHT $>>$ ALIGN-IP-LEFT. Thirdly, the constraint in each demotion of constraint hierarchical ranking during different stages is as follows: NEW-IP constraint moves from the undominated position to the dominated position in the hierarchy; ALIGN-IPRIGHT and ALIGN-IP-LEFT constraints move from the dominated position to the lower position in the hierarchy. Through the specific analysis, the researcher draws a conclusion that the varied reasons affect the nonnative speakers to master the distribution of sentence stress due to their incorrect position in the demotion of constraint hierarchical ranking.

\section{Introduction}

From the perspective of linguistics, the definition of the stress, as Robert Ladd holds, is always used as "supersegment feature of fundamental frequency, duration and intensity" [1]. Mispronunciation of English sentence stress is always a striking phenomenon which exists and should be paid more attention to avoid the "Foreign accent" [2]. Incorrect placement of sentence stress will be detrimental to the comprehensible message which the speaker intends to convey and to the understanding in utterance. Therefore, mastering the sentence stress properly will not only get a better command of English rhythm and intonation, but also improve the oral expression and communicational comprehension ability. Acquisition of English sentence stress has been a challenge in the study of English. Although lots of stress theories made many proper explanations, the effect is not ideal enough. Lots of scholars unanimously agree that stress, as linguistic phenomenon, could be studied by reference to acoustic correlates, and a wealth of diverse views has been witnessed in this regard. Some scholars thought the choices of intonation are definitely not arbitrary $[3,4]$. S. Schmerling, as a specialist in linguistic theory with a particular interest in the theory of syntax, wrote a book Aspects of English Sentence Stress. In her book, within the conceptual framework of generative transformational grammar, Schmerling's concern is not with the phonetic nature of stress, rather using a working definition of stress as subjective impression of prominence [5]. In Arciuli, Monaghan, and Seva's paper "Learning to Assign Lexical Stress during Reading Corpus, Behavioral, and Computational Investigations," they used a triangulation of corpus, behavioral, and computational modeling techniques to analyze the beginnings and endings of English bisyllabic words, 
which are highly predictive of stress position, but that endings are more reliable cues in texts. These results reflect the gradual process of learning the statistical properties of written input and provide key constraints for adequate models of reading. Ulrike Domahs' "Word Stress Assignment in German, English and Dutch: Quantity Sensitivity and Extrametricality Revisited" shows that word stress is not fixed to a certain position $[6,7]$.

There is, however, no consensus on the actual stress assigning algorithms and the role of quantity [8-10]. Over the past three decades, a concept has repeatedly invoked in the descriptions of English pronunciation and intonation [8, 11-15]. Therefore, sentence stress distribution plays a significant role in English. Phonological skills are different fundamentally from linguistic skills in morphology [16], syntax, or semantics in that language learning. A study by Ioup (1984) showed that native speakers of English could identify the stress correctly while nonnative speakers are not able to do so [17]. Within the field of sentence stress, the most frequently studied area is accentuation. Although there are lots of researchers and theories related to the stress, they rarely get an agreement with each other upon how to distribute the sentence stress in English. There are few effective theories to follow, and the empirical studies related investigating how to distribute the sentence stress in English based on Optimality Theory still leave more room for improvement. According to the variety of the individual speakers, how to acquire the correct distribution of the sentence stress step by step needs further empirical practice.

This paper takes four principles of distribution of English sentence stress as constraints which are chosen from the related theories. Two major advantages lie in its powerful explanation which incorporates the universality and variation in linguistic (Zuraw, 2003). The distinction is the constraint hierarchy. Therefore, this present study adopts the Optimality Theory and software Praat as both empirical and theoretical methods to study the accentuation in sentence stress. For the Optimality Theory as constraint-based phonological theory, it is fairly powerful in explaining the phenomenon in many languages. Until now, a lot of researches have proved the fact that the Optimality Theory can be used to study language universals in phonology, syntax, and so on. But few studies are drawn on English sentence stress.

\section{Materials and Methods}

2.1. Optimality-Theoretic Analysis. Optimality Theory, put forward by Prince and Smolensky [18], has a dramatic impact on most areas in linguistics besides phonology. The research questions of this present paper focus on an Optimality Theory analysis of the acquisition of sentence stress and have benefited from the related theoretic analysis. Firstly, the empirical studies investigating how to distribute the sentence stress in English based on Optimality Theory still leave more room for improvement. Secondly, based on Optimality Theory [19], previous studies and theories on the placement of the sentence stress do not agree with each other upon how to distribute the sentence stress in English; the related researchers have not reached a consensus on whether nonnative speakers always undergo the process of constraint demotion in the acquisition of sentence stress. Finally, according to the analysis, confirming the acquisition of placement of sentence stress which varies with the principles of sentence stress distribution in English is important [20].

2.2. Subjects. Three native speakers of English participate in the research project as a control to confirm assumptions about the native English constraint hierarchy and provide baseline data for comparison with and accuracy judgments of the nonnative's performance. 15 subjects out of 60 were ruled out, and the others were successfully selected to participate in this research as nonnative speakers.

From the information presented in Table 1, it is clear that the subjects' average age is around 20 years old (mean$=19.9$ ); their average time of English language learning is over 8 years $($ mean $=8.6)$ and all of them had passed an English pronunciation course, which consists of nearly 10 tokens of the target stress segments including word stress and sentence stress for each subject. A total of 200 tokens are large enough to reflect the pronunciation accuracy of the selected subjects. With the help of the SPSS 20.0, the present study produces the related tests, including the $t$-test of the subjects.

2.3. Instruments and Materials. The instruments and materials employed in this present study include experimental materials for reading and a computer equipped with two software packages Praat and SPSS 20.0 for data collection and analysis.

Praat, a freeware program for the phonetic and phonological studying, is used to collect, analyze, label, manipulate, and synthesize acoustic speech signal to create the spectrograms or statement [21]. The software also can emphasize to indicate the waveform, intensity, sonogram, pitch, duration, and other details, and filter frequencies, or to offer a wide range of standard and nonstandard procedures, including spectrographic analysis, articulatory synthesis, and neural networks, which can be used for academic paper and monograph. In the present study, the spectrograms of distribution of sentence stress are used to contrast the nonnative and native speakers' language to discover the adverse effects or error detection and change them and to identify the principles on sentence stress.

The experimental material was selected from an authoritative textbook entitled Sally's First Train Ride published by Foreign Language Teaching and Research Press, which includes 9 sentences as follows:

Sentence 1: suddenly, a middle-aged lady got on the train and sat opposite Sally. Sentence 2: "Hello, little girl," she said. Sentence 3: Sally did not answer, but looked at her curiously. Sentence 4: the lady began to make up her face. Sentence 5: "Why are you doing that?" Sally asked. Sentence 6: "To make myself beautiful," the lady answered. Sentence 7: she put away her compact and smiled kindly. Sentence 8: "But you are still ugly," Sally said. Sentence 9: sally was amused, but I was very embarrassed. 
TABLE 1: The $t$-test of the subjects.

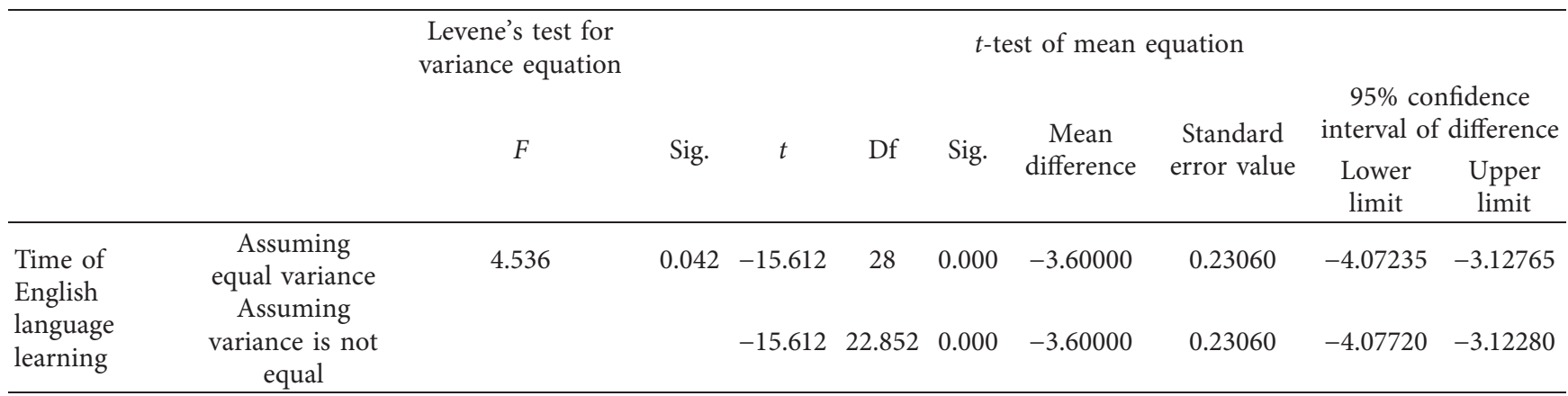

The statistics show that the nonnative speakers' groups are significant because $P<0.05$, which can conclude that the groups are reliable for the following process.

This paper takes sentence 3 (Sally did not answer, but looked at her curiously) as an example (consisting of 9 words).

2.4. Experimental Preparation. The experiment makes an experimental design and consults with some professors in the present study and then carries out the related previous studies to verify the principles of sentence stress distribution in English. Finally, based on the preliminary investigations, the experiment takes the most important step of doing all the tremendous work of recording, data collecting, and data labeling. This paper presents four principles of sentence stress distribution: content words stressed principle, rightmost words stressed principle, leftmost words stressed principle, and new information priority principle.

2.5. Data Collection and Processing. The subjects are required to read aloud the material (Sally's First Train Ride) for three times a day in a linguistic lab with the computers equipped with Praat during a period of approximately three months.

2.5.1. Data Collection. In the experiment instrument, firstly, for setting the sampling rate of Praat, in most cases, the default $(22 \mathrm{kHz})$ will be more than sufficient. If the computer has less disk space, a lower sampling rate $(11 \mathrm{kHz})$ is enough. If the recording is recorded at $\mathrm{CD}$ quality, select the highest sampling rate $(44 \mathrm{kHz})$. Secondly, the present study used high-quality microphones, because some ordinary computers microphones will not pick up frequencies below $100 \mathrm{~Hz}$. This means it will store 44100 samples per second per channel (= about 176400 bytes with a 16-bit sound card). The present study chooses the sampling rate of $22 \mathrm{kHz}$; on the other side, the researcher and other colleagues make full preparation for the computers and microphones and show the subjects the material on the computer screen to avoid the noise which may be produced by rustling the paper. The three native speakers were invited to perform the same reading material in the same lab. The subjects were not informed of the goal of the present study or the principles of sentence stress distribution in English to be examined. They were just reminded to do the recording naturally and clearly.

All the reading files of the nonnative speakers' subjects were saved in MP3 format in folder named nonnative speakers' Reading Files, and the recording files for the three native speakers were saved in MP3 format in folder named Native Reading Files, for auditory evaluation and acoustic analysis. Before the next step for data labeling, the 18 subjects are divided into two groups: nonnative and native.

2.5.2. Data Labeling. All the saved reading records (including 15 subjects' and 3 native speakers') were labeled by Praat. The labeling was extremely time-consuming and painstaking. To accomplish this task, the researcher received lots of kind help from the application of Praat software to analyze the sentence by the 18 subjects.

The data collected and labeled was divided into four groups to represent content words stressed principle, new information priority principle, rightmost words stressed principle, and leftmost stressed principle, respectively. Streaming was done by means of auditory evaluation given by 18 subjects. Through the Praat, the spectrograms from two groups are as follows.

Figure 1 is spectrogram of intensity of sentence 3 from nonnative subjects. In this sentence, the stressed words can be placed clearly through the above spectrogram. That is, Sally, answer, looked, curiously.

Figure 2 is the spectrogram of intensity of sentence 3 from native subjects. In this sentence, the stressed words can be placed clearly through the above spectrogram. That is, not, curiously.

\section{Main Results}

From the above study of Optimality Theory applied in English sentence stress, the present study holds that the Optimality Theory is an influential and powerful phonological theory, and the major advantage of Optimality Theory lies in its explanatory power which incorporates the universality and variation of language. The Optimality Theory can explain phonological phenomena and native language transfer through its constraints and the specific ranking of constraints. This research gets a better view of the sentence stress placement and of the path of constraint demotion, specifically, which constraints are demoted in earlier stage of acquisition and which constraints are demoted in later stage, and the constraint movement. The main results are as follows. 


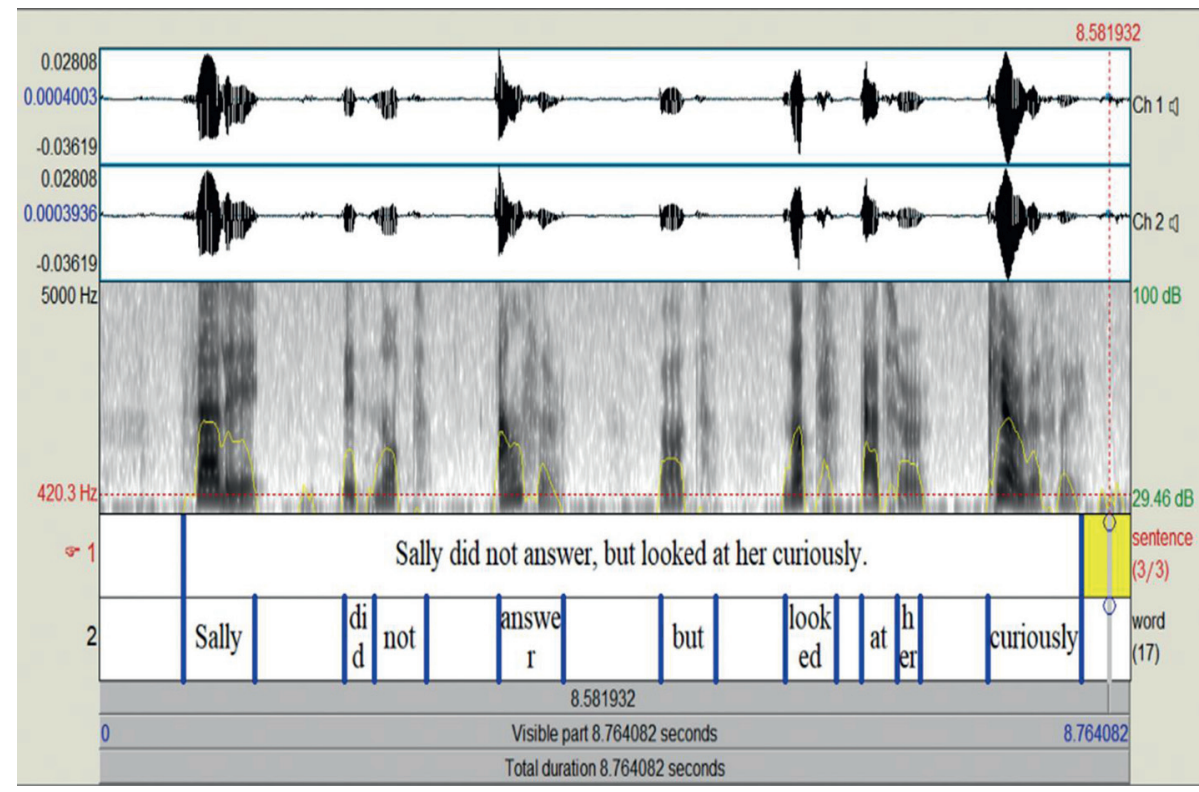

FIGURE 1: Spectrogram of sentence 3 from nonnative subjects.

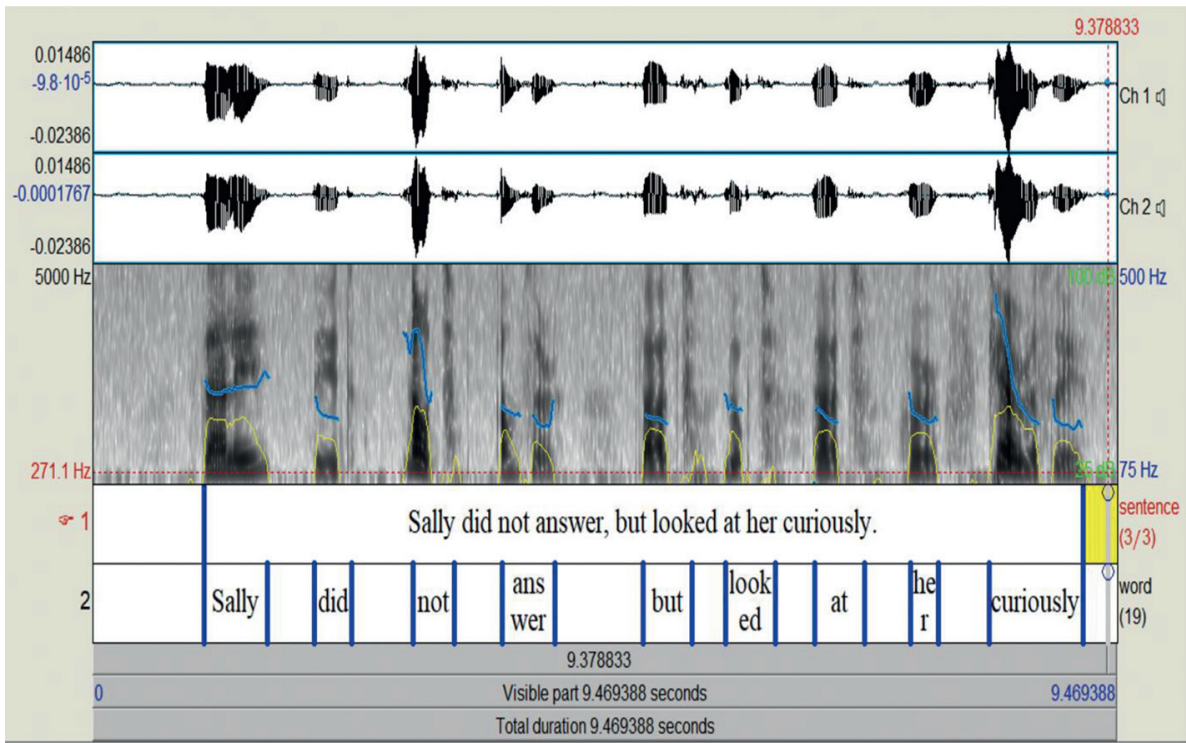

FIgURE 2: Spectrogram of sentence 3 from native subjects.

3.1. Results and Analysis of Constraints in Sentence Stress Distribution. The principles for placement of sentence stress sometimes are incompatible with each other, so the conflicts should be solved. The way based on the Optimality Theory via hierarchical rankings of the constraints can give an optimal output [22]. The present study adopts the following four constraints as working constraints interacting to yield the output stress patterns.

(a) DEP-IO (P): all prominence achieved in the output must have counterpart in the input. Here, for this present study, the constraint DEP-IO (P) accords with the principle of content stress.

(b) ALIGN-IP-RIGHT: prominence is aligned with the rightmost word. (c) ALIGN-IP-LEFT: prominence is aligned with the rightmost word.

(d) NEW-IP: prominence is achieved on new information.

3.2. Results and Analysis of Constraint Hierarchy Rankings. The hierarchy rankings are all based on the real data regarding the violation frequency of each constraint produced by the subjects in the given material.

To reveal how those violable constraints are ranked at the discrete acquisition stages and how the constraints are moved from each stage to another, this part analyzes the violations of each constraint and summarizes the constraint hierarchies from the violation of constraints produced by the 
different group of subjects. According to Optimality Theory, stating that the minimal violation is the satisfied constraint, so the more frequently a constraint is violated, the lower is ranked in the constraint hierarchy.

The first constraint is DEP-IO (P), which is violated when the generally unstressed words are accented, especially with contrastive or emphatic information or by misplacement of stress. In such situation, all prominence achieved in the output may be more than that in the input [23]. In the given material, violations of DEP-IO (P) were opposite in sentence 1; hello and she in sentence 2; did in sentence 3; up in sentence 4; why in sentence 5; myself in sentence 6; who and that in sentence 8 ; and $I$ in sentence 9 .

The constraint ALIGN-IP-RIGHT always stipulates that the prominence should be achieved on the rightmost word. In the given material, violations of ALIGN-IP-RIGHT were suddenly, middle, lady, got, train, sat, and opposite in sentence 1, hello and little in sentence 2, did, answer, and looked in sentence 3, began and make in sentence 4, why and doing in sentence 5, myself in sentence 6, put, compact, and smiled in sentence 7, still in sentence 8, Sally amused, and $I$ in sentence 9 .

The constraint ALIGN-IP-LIFT stipulates that the prominence should be achieved on the leftmost word. In the given material, violations of ALIGN-IP-LEFT were middle, lady, got, train, sat, opposite, and Sally in sentence 1, little and girl in sentence 2, did, answer, looked, and curiously in sentence 3, began, make, and face in sentence 4, doing and asked in sentence 5, myself, beautiful, and answered in sentence 6, put, compact, smiled, and kindly in sentence 7, still in sentence 8 , and embarrassed and $I$ in sentence 9 .

The constraint NEW-IP stipulates that the prominence should be achieved on new information, not old one. Old information refers to the information which is mentioned previously or can be contrasted from the context. In this given material, even if Sally appears for 5 times, lady for 3 times, the Sally in sentence 9 still should be stressed for contrasting as new information. Thus, the violations of NEW-IP were Sally in sentence 5 and sentence 8 , she in sentence 7 , said in sentence 8 , her in sentence 4 and sentence 7 , and lady in sentence 6 .

\subsubsection{The Constraint Hierarchy Rankings of Nonnative} Speakers. To get the violation rate of four constraints of each nonnative speaker subject clearly, the present study generated a table according to the real data regarding the violation frequency of each constraint produced by the nonnative speakers in the given material.

According to Table 2, the present study introduces a histogram graph to see the violation rate of four constraints of nonnative speaker subjects clearly.

From Figure 3, violation frequency of each constraint incurred by the nonnative subjects illustrates the constraint ranking of nonnative speakers as follows: DEP-IO $>>$ NEWIP $>>$ ALIGN-IP-LEFT $>>$ ALIGN-IP-RIGHT.

3.2.2. The Constraint Hierarchy Rankings of Native Speakers. To reveal the violation rate of four constraints of each native speaker subject, the present study generated another table according to the real data regarding the violation frequency of each constraint produced by the native speakers in the given material.

According to Table 3 , the present study produces a histogram graph to see the violation rate of four constraints of native subjects clearly.

For the three native speakers, the violations of each constraint were as above Figure 4 and also referred to as the target model for the distribution of the English sentence stress. From Figure 4, the violation frequency of each constraint incurred by the native subjects illustrates the constraint ranking of the native speakers as follows: NEWIP $>>$ DEP-IO >> ALIGN-IP-RIGHT $>>$ ALIGN-IP-LEFT.

3.3. Results and Optimality-Theoretic Analysis. For example, Input: sally did not answer, but looked at her curiously, the asterisk "*" marks each violation of a constraint, and the exclamation mark "!" indicates the fatal violation of a constraint, which will result in the rejection of a candidate. The symbol "draws the attention to the optimal or winning candidate [24]. There are three candidates: $\mathrm{C}_{\mathrm{ANDa}}$, $\mathrm{C}_{\mathrm{ANDb}}$, and $\mathrm{C}_{\mathrm{AND}}$, which are all chosen from the two groups. $\mathrm{C}_{\mathrm{ANDa}}$ and $\mathrm{C}_{\mathrm{ANDc}}$ represent the nonnative subjects group, while $\mathrm{C}_{\mathrm{ANDb}}$ represents the native subjects group. On the other side, four CONs are presented in the tableaux too. They represent the four constraints: $\mathrm{C}_{\mathrm{ONA}}$ represents NEWIP constraint, $\mathrm{C}_{\mathrm{ONB}}$ represents $\mathrm{DEP}-\mathrm{IO}$ constraint, $\mathrm{C}_{\mathrm{ONC}}$ represents ALIGN-IP-RIGHT constraint, and $\mathrm{C}_{\text {OND }}$ represents ALIGN-IP-LEFT constraint.

In Table $4, \mathrm{C}_{\mathrm{ANDa}}$ violates $\mathrm{C}_{\mathrm{ONA}}$ once, violates $\mathrm{C}_{\mathrm{ONB}}$ twice, and violates $\mathrm{C}_{\mathrm{ONC}}$ once; $\mathrm{C}_{\mathrm{ANDb}}$ violates $\mathrm{C}_{\mathrm{ONA}}$ three times, violates $C_{\text {ONC }}$ once, and violates $C_{O N D}$ once; $C_{A N D c}$ violates $\mathrm{C}_{\mathrm{ONA}}$ twice and violates $\mathrm{C}_{\mathrm{ONB}}$ twice too. Therefore, based on Optimality Theory, $\mathrm{C}_{\mathrm{ANDb}}$ and $\mathrm{C}_{\mathrm{ANDc}}$ violate the highest ranked constraint, which should be rejected [7]. $\mathrm{C}_{\mathrm{ANDa}}$ is finally chosen as optimal or winning candidate.

In Table 5, $\mathrm{C}_{\mathrm{ANDa}}$ violates $\mathrm{C}_{\mathrm{ONA}}$ twice, violates $\mathrm{C}_{\mathrm{ONB}}$ once, and violates $C_{\mathrm{OND}}$ once; $\mathrm{C}_{\mathrm{ANDb}}$ violates $\mathrm{C}_{\mathrm{ONB}}$ three times, violates $\mathrm{C}_{\mathrm{ONC}}$ once, and violates $\mathrm{C}_{\mathrm{OND}}$ once; $\mathrm{C}_{\mathrm{ANDc}}$ violates $\mathrm{C}_{\mathrm{ONA}}$ twice and violates $\mathrm{C}_{\mathrm{ONB}}$ once too. Therefore, based on Optimality Theory, $\mathrm{C}_{\mathrm{ANDa}}$ and $\mathrm{C}_{\mathrm{ANDc}}$ violate the highest ranked constraint, which should be rejected. $\mathrm{C}_{\mathrm{ANDb}}$ is finally chosen as optimal or winning candidate.

\section{Discussion}

From the above results, it is obvious that nonnative speakers undergo a process of constraint demotion in the different acquisition of the distribution of the English sentence stress.

4.1. Research on Difference of Occurring Frequency of Violated Constraints. The difference between different stages lies in the difference of occurring frequency of violated constraints [25]. So, the nonnative speakers undergo a path (pattern) of constraint demotion: NEW-IP constraint moves from the undominated position to the dominated position in the hierarchy, ALIGN-IP-LEFT and ALIGN-IP-RIGHT constraints move from the dominated position to the lower 
TABLE 2: The violation rate of four constraints of nonnative speakers.

\begin{tabular}{lcccc}
\hline Subjects & $\begin{array}{c}\text { Violation rate of new } \\
\text { information priority principle } \\
(\%)\end{array}$ & $\begin{array}{c}\text { Violation rate of content } \\
\text { words stressed principle (\%) }\end{array}$ & $\begin{array}{c}\text { Violation rate of rightmost } \\
\text { words stressed principle (\%) }\end{array}$ & $\begin{array}{c}\text { Violation rate of leftmost } \\
\text { words stressed principle (\%) }\end{array}$ \\
\hline 1 & 25.71 & 47.14 & 11.43 & 15.71 \\
2 & 27.14 & 34.29 & 8.71 & 22.86 \\
3 & 25.71 & 42.86 & 5.71 & 22.86 \\
4 & 32.86 & 44.29 & 12.86 & 17.14 \\
5 & 32.86 & 35.71 & 7.14 & 18.57 \\
6 & 38.57 & 41.43 & 8.57 & 12.86 \\
7 & 37.14 & 42.86 & 14.29 & 24.29 \\
8 & 20.00 & 41.43 & 4.29 & 18.57 \\
9 & 37.14 & 40.00 & 11.43 & 22.86 \\
10 & 31.43 & 34.29 & 8.57 & 22.86 \\
11 & 28.57 & 40.00 & 10.00 & 18.57 \\
12 & 27.14 & 44.29 & 12.86 & 14.29 \\
13 & 31.43 & 41.43 & 14.29 & 17.14 \\
14 & 22.86 & 45.71 & 15.71 & 21.43 \\
15 & 27.14 & 35.71 & 10.76 & 18.76 \\
\hline Average & 29.71 & 40.76 & & \\
\hline
\end{tabular}

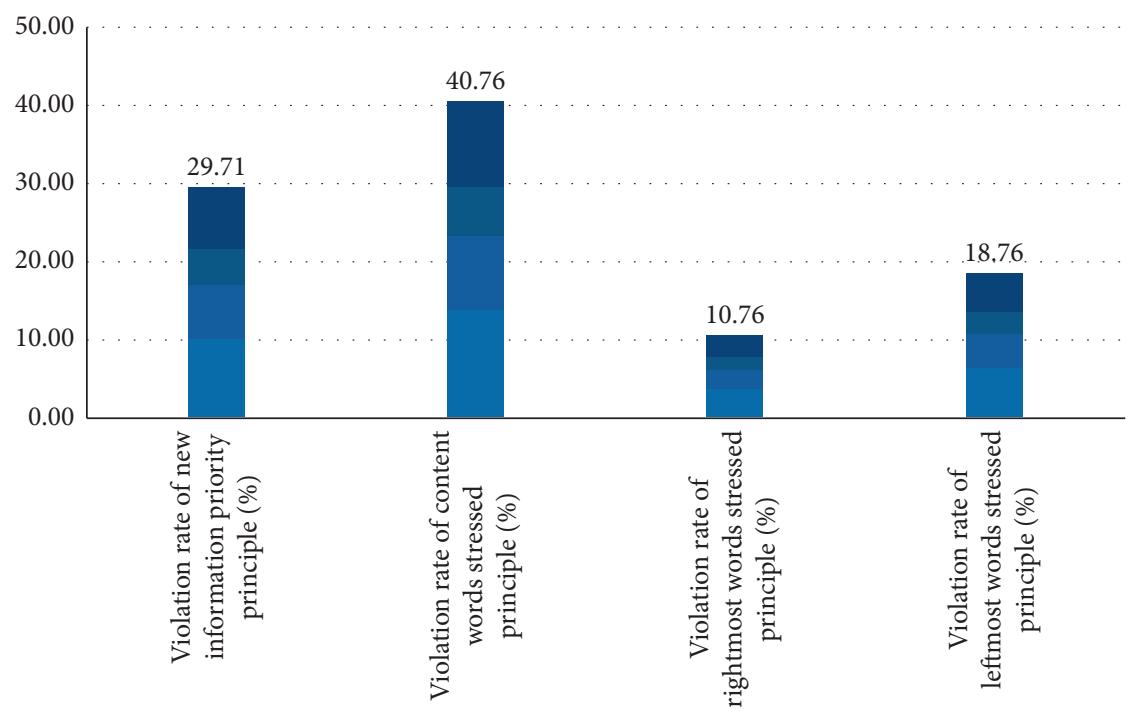

Violation rate

FIGURE 3: The histogram graph of violation rate of four constraints of nonnative subjects.

TABLE 3: The violation rate of four constraints of native subjects.

\begin{tabular}{lcccc}
\hline Subjects & $\begin{array}{c}\text { Violation rate of new } \\
\text { information priority principle } \\
(\%)\end{array}$ & $\begin{array}{c}\text { Violation rate of content } \\
\text { words stressed principle (\%) }\end{array}$ & $\begin{array}{c}\text { Violation rate of rightmost } \\
\text { words stressed principle (\%) }\end{array}$ & $\begin{array}{c}\text { Violation rate of leftmost } \\
\text { words stressed principle (\%) }\end{array}$ \\
\hline 1 & 44.29 & 31.43 & 17.14 & 7.14 \\
2 & 47.14 & 35.71 & 15.71 & 1.43 \\
3 & 42.86 & 30.00 & 22.86 & 4.29 \\
\hline Average & 44.76 & 32.38 & 18.57 & 4.29 \\
\hline
\end{tabular}

position in the hierarchy, and DEP-IO constraint is demoted below the NEW-IP constraint, from the top position to second. The NEW-IP constraint is from the second position to the top. ALIGN-IP-LEFT and ALIGN-IP-RIGHT constraints just change their position with each other.
As above, through comparing with the path of constraint demotion of all subjects, the present study is a theoretic analysis of the acquisition of English sentence stress based on Optimality Theory. With the guidance of the software Praat, the research took a detailed data recording and data labeling. 


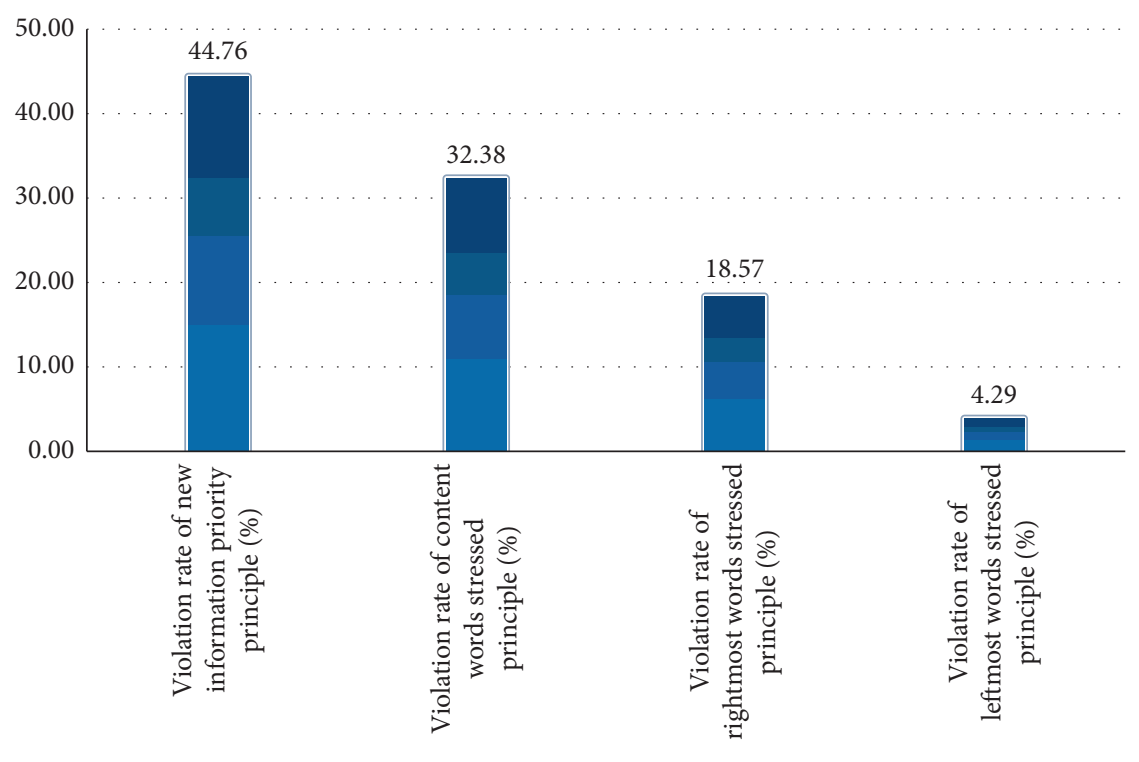

Violation rate

FIgURE 4: The histogram graph of violation rate of four constraints of native subjects.

TABLE 4: An optimality-theoretic analysis of nonnative speakers.

\begin{tabular}{|c|c|c|c|c|}
\hline Input: Sally did not answer, but looked at her curiously & DEP-IO & NEW-IP & ALIGN-IP-LEFT & ALIGN-IP-RIGHT \\
\hline $\mathrm{C}_{\mathrm{ANDa}}$. Sally did not answer, but looked at her curiously & $*$ & $* *$ & * & \\
\hline $\mathrm{C}_{\mathrm{ANDb}}$. Sally did not answer, but looked at her curiously & $* * * !$ & & * & * \\
\hline $\mathrm{C}_{\text {ANDc. }}$ Sally did not answer, but looked at her curiously & $* * !$ & ** & & \\
\hline
\end{tabular}

TABLE 5: An optimality-theoretic analysis of native speakers.

\begin{tabular}{|c|c|c|c|c|}
\hline Input: Sally did not answer, but looked at her curiously & NEW-IP & DEP-IO & ALIGN-IP-RIGHT & ALIGN-IP-LEFT \\
\hline $\mathrm{C}_{\mathrm{ANDa}}$. Sally did not answer, but looked at her curiou & $* * !$ & * & & * \\
\hline $\mathrm{C}_{\mathrm{ANDb}}$. Sally did not answer, but looked at her curiously & & $* * *$ & $*$ & * \\
\hline $\mathrm{C}_{\mathrm{ANDc}}$. Sally did not answer, but looked at her curiously & $* *$ ! & * & & \\
\hline
\end{tabular}

Then, from the spectrograms of those acoustic data, the research obtained the specific stressed words for each sentence. Secondly, based on the analysis of Optimality Theory, the research has achieved the following findings:

(a) There are four main principles as the constraints in the distribution of sentence stress: content words stressed principle, rightmost words stressed principle, leftmost words stressed principle, and new information priority principle.

(b) The nonnative speakers undergo the demotions of constraint hierarchical ranking with obvious path which varies with different stages in learning process of the distribution of English sentence stress: DEPIO $>>$ NEW - IP $>>$ ALIGN-IP-LEFT $>>$ ALIGN-IPRIGHT.

(c) The native speakers also undergo the demotion of constraint hierarchical ranking: NEW-IP $>>$ DEPIO $>>$ ALIGN-IP-RIGHT $>>$ ALIGN-IP-LEFT.

(d) The constraints in each demotion of constraint hierarchical ranking during different stages and of native subjects are moved along this path: NEW-IP constraint moves from the undominated position to the dominated position in the hierarchy; ALIGN-IPRIGHT and ALIGN-IP-LEFT constraints move from the dominated position to the lower position in the hierarchy.

Through the specific analysis, it is found that the varied reasons affect the nonnative speakers to master the distribution of sentence stress due to their incorrect position in the demotion of constraint hierarchical ranking. They have not mastered the English sentence stress theory appropriately. Most of them are familiar with the content words stressed principle, but do not master the new information principle. On the other side, without effective acoustic software, nonnative speakers cannot find their misplacement of English sentence stress directly. Using the spectrograms from Praat to contrast the nonnative and native speakers' distribution of English sentence stress, it will help them to discover the adverse effects or error detection. Then, through enough imitation and more practice, "Foreign accent" will be overcome easily. 
4.2. Discussion on Theoretical Implications. Theoretically, the present study has the following theoretical implications based on the framework of Optimality Theory:

(a) Through this study, Optimality Theory proves to be a powerful framework to explain the distribution of English sentence stress by the exemplified interpretation of Optimality Theory. The study also proves that the Optimality Theory can be applied to the acoustic acquisition for nonnative speakers successfully.

(b) The demotion of constraint hierarchical ranking in the study proves the authenticity of some scholars' related research and the power of Optimality Theory; at the same time, it can shed some light on the further study in the related area.

(c) The researcher has collected enough related literature to enlarge the notion of the distribution of English sentence stress.

However, the pure theoretical analysis without empirical data collected systematically always has a comparatively weak defect to study the accentuation in English sentence stress. Thus, the study also conducted a specific experiment for empirical study. On the one side, through the labeling data by Praat, the nonnative speakers can distinguish the specific mistakes they made in the acquisition of English sentence stress distinctly; on the other side, under the guidance of the software Praat, the nonnative speakers can improve their acquisition of English sentence stress more proficiently by enough practice.

\section{Conclusions}

Through the specific analysis, it is found that the varied reasons affect the nonnatives to master the distribution of sentence stress due to their incorrect position in the demotion of constraint hierarchical ranking. On the one side, they have not mastered the English sentence stress theory appropriately. Most of them are familiar with the content words stressed principle, but do not master the new information principle. On the other side, their imitation and more practice are not sufficient.

\section{Data Availability}

The authors use simulation data, and their model and related hyperparameters are provided in the paper.

\section{Conflicts of Interest}

The authors declare that they have no conflicts of interest regarding the publication of this paper.

\section{Acknowledgments}

This work was supported by Key Projects of Humanities and Social Sciences in Anhui Province: Textual analysis of "One Belt and One Road" from Chinese and foreign news corpus (SK2018A0870) and by the Key Program in the Youth Elite Support Plan in Universities of Anhui Province in 2021 by the Quality Improvement Program of Ministry of Education (2020-2023)-Course construction of New Practical English.

\section{References}

[1] D. Robert Ladd, Intonational Phonology, Cambridge University Press, Cambridge, UK, 2008.

[2] K. M. Ryan, "Prosodic end-weight reflects phrasal stress," Natural Language \& Linguistic Theory, vol. 37, no. 1, pp. 315-356, 2019.

[3] P. Francuz, "The impact of audio information intonation on understanding television news content," Psychology of Language and Communication, vol. 14, no. 1, pp. 71-86, 2010.

[4] F. D. W. Maynard, "Prosodic features of bad news and good news in convers- ation," Language in Society, vol. 27, pp. 195-219, 1998.

[5] S. F. Schmerling, Aspects of English Sentence Stress, University of Texas Press, Austin, TX, USA, 2011.

[6] A. J. Holliman, S. Critten, C. Wood, H. Cunnane, and C. Pillinger, "Examining the independent contribution of prosodic sensitivity to word reading and spelling in early readers," Reading and Writing, vol. 30, no. 3, pp. 509-521, 2017.

[7] U. Domahs, I. Plag, and R. Carroll, "Word stress assignment in German, English and Dutch: quantity-sensitivity and extrametricality revisited," The Journal of Comparative Germanic Linguistics, vol. 17, no. 1, pp. 59-96, 2014.

[8] J. Anderson-Hsieh and H. Venkatagiri, "Syllable duration and pausing in the speech of Chinese ESL speaker," TESOL Quarterly, vol. 28, no. 4, pp. 807-812.

[9] T. Anh-Thu' Nguyen, "Prosodic transfer in Vietnamese acquisition of English contrastive stress patterns," Journal of Phonetics, vol. 36, pp. 158-190, 2008.

[10] W. Cardoso, "The variable development of English word-final stops by Brazilian Portuguese speakers: a stochastic optimality theoretic account," Language Variation and Change, vol. 19, no. 3, pp. 219-248, 2007.

[11] M. A. K. Halliday, Intonation and Grammar in British English, The Hague, Mouton, LA, USA, 1967.

[12] J. A. Bright and G. P. McGregor, "Teaching English as a second language," Longman, Sage Publications, London, UK, 1970.

[13] J. Clark and C. Yallop, An Introduction to Phonetics and Phonology, Blackwell, Oxford, UK, 1995.

[14] G. Abbott and P. Wingard, The Teaching of English as an International Language, Collins, Glasgow, Scotland, 1981.

[15] A. Cruttenden, Gimsou's Pronunciation of English, Beijing: Foreign Language Teaching and Research Press, 2001.

[16] W. T. Wang, "A comparative study and phonological analysis of the intonation of English complex interrogatives with dual question words," A Thesis for the M.A. Degree, Jinan University, Guangzhou, China, 2013.

[17] F. R. Eckman, "From phonemic differences to constraint rankings," Research on Second Language Phonology. Studies in Second Language Acquisition, vol. 26, pp. 513-549, 2004.

[18] A. Prince and P. Smolensky, "Optimality theory: constraint interaction in generative grammar," Science, vol. 275 , no. 4, 1993.

[19] N. Merchant and J. Riggle, "OT grammars, beyond partial orders: ERC sets and antimatroids," Natural Language \& Linguistic Theory, vol. 34, no. 1, pp. 241-269, 2016.

[20] J. Riggle and S. Zukoff, "Prosodic identity in copy epenthesis," Natural Language \& Linguistic Theory, vol. 36, no. 2, pp. 637-684, 2018. 
[21] J. Yamashita and N. Jiang, "L1 infl- uence on the acquisition of L2 collocations: Japanese ESL users and EFL learners acquiring English colloca- tions," TESOL Quarterly, vol. 44, no. 4, pp. 647-668, 2012.

[22] D. Gutiérrez Palma, "Optimal cliticplacement in tiwa," North East Linguistic Society, vol. 1, no. 1, pp. 243-256, 2017.

[23] R. Bawden, "Towards the generation of dialogue acts in socioaffective ECAs: a corpus-based prosodic analysis," Language Resources and Evaluation, vol. 50, no. 4, pp. 821-838, 2016.

[24] T. Clavel, "An OT analysis of do-support across varieties of German," The Journal of Comparative Germanic Linguistics, vol. 21, no. 1, pp. 75-129, 2018.

[25] Y. Haralambous, J. Sauvage-Vincent, and J. Puentes, "A hybrid (visual/natural) controlled language," Language Resources and Evaluation, vol. 51, no. 1, pp. 93-129, 2017. 